\title{
Babyfaces, Trait Inferences, and Company Evaluations in a Public Relations Crisis
}

\author{
GERALD J. GORN \\ YUWEI JIANG \\ GITA VENKATARAMANI JOHAR*
}

\begin{abstract}
We investigate the effects of babyfaceness on the trustworthiness and judgments of a company's chief executive officer in a public relations crisis. Experiment 1 demonstrates boundary conditions for the babyfaceness-honesty trait inference and its influence on company evaluations. Experiment 2 shows that trait inferences of honesty are drawn spontaneously but are corrected in the presence of situational evidence (a severe crisis) if cognitive resources are available. We demonstrate that these babyface-trait associations underlie evaluations by reversing the babyface effect on judgments in (a) experiment 3 , where a priming task creates associations counter to the typical babyface-unintentional harm stereotype, and $(b)$ experiment 4 , which creates a situation where innocence is a liability.
\end{abstract}

$\mathrm{S}_{\mathrm{s}}$ earch the Web for today's business news or read the business section of the newspaper and you will likely come across a headline about a company facing a public relations (PR) crisis. Take the recent headline, "Edelman Eats Humble Pie, Unmasked as Force behind Wal-Mart Blog; PR Giant Does Damage Control" (Frazier 2006). The accompanying article, which includes a photo of Richard Edelman, contains Edelman's apology for a fake blog that his firm created on behalf of Wal-Mart. The question we address is how consumers will respond to Edelman's public apology for the "error in failing to be transparent about the identity of the two bloggers from the outset." How will Edelman's apology influence consumer liking for the Edelman and Wal-Mart brands? We believe that Edelman's photo in the news article-specifically, whether he is per-

*Gerald J. Gorn is Chair Professor, Department of Marketing, Hong Kong University of Science and Technology, Clear Water Bay, Kowloon, Hong Kong (mkgorn@ust.hk). Yuwei Jiang is a doctoral candidate of marketing, Hong Kong University of Science and Technology, Clear Water Bay, Kowloon, Hong Kong (jiangyw@ust.hk). Gita V. Johar is Meyer Feldberg Professor of Business at the Graduate School of Business, Columbia University (gvj1@ columbia.edu). Order of authorship is alphabetical. All authors contributed equally to the article and thank Jennifer Argo, Darren Dahl, Marv Goldberg, and Leslie Zebrowitz for their very helpful comments. The authors also thank the editor, associate editor, and reviewers for their suggestions, which were invaluable in reshaping the article. This research was supported by a grant from the Hong Kong Government Grant Council (HKUST6502/06H) and by support from the Columbia Business School research fund. Correspondence should be sent to Gerald J. Gorn.

John Deighton served as editor and Ann McGill served as associate editor for this article.

Electronically published March 10, 2008 ceived to have a "babyface" (i.e., large eyes, small nose, high forehead, and small chin) or a mature face-will be one of the determinants of their response.

While prior research has documented the association of babyfaceness with certain traits such as innocence, it has neglected to pin down how these associations have downstream consequences. Further, the literature suggests that the effects of babyfaceness are spontaneous but has not empirically documented the spontaneity of this effect or examined conditions under which this effect is corrected by contextual cues. In four experiments set in a PR crisis context, we investigate boundary conditions of the effect of face type on the perceived credibility of a chief executive officer (CEO) and, consequently, on company evaluations. Our findings shed light on when and how the face of a company spokesperson affects attitudes toward the company.

\section{THEORETICAL FRAMEWORK}

Appearances bias impressions. Is the person attractive? Is he or she tall? Does he or she have a babyface? Babyfaced people are perceived as kinder, warmer, and physically weaker than maturefaced people (Berry and McArthur 1985; McArthur and Apatow 1983-84). They are also perceived as more honest and more naive (Berry and Brownlow 1989; Berry and McArthur 1985; McArthur and Apatow 1983-84). It is generally accepted that associations between babyfaceness and specific personality traits are chronic. All species protect their young, so the babyface effect has its roots in an adaptive function. However, the babyface stereotype 
reflects an overgeneralization beyond this adaptive function (Zebrowitz 1997).

Friedman and Zebrowitz (1992) provide limited support for the malleability of these chronic associations. Participants in one condition of their experiment were presented with babyfaced males and maturefaced females to induce associations counter to the stereotype (e.g., that males are maturefaced). This gender-face type matching treatment was, however, not successful in reversing chronic face type-trait associations. Babyface associations were eliminated for some traits and held for others.

Some research has examined the consequences of these trait inferences. Babyfaced defendants are more likely to be convicted of crimes of negligence, such as leaving something out on a tax return, rather than crimes of intention (Zebrowitz and McDonald 1991). Crimes of negligence presumably reflect carelessness, a plausible babyface trait, rather than dishonesty, which is not associated with babyfaces. Zebrowitz, Tenenbaum, and Goldstein (1991) found that babyfaced applicants were rated higher than maturefaced ones for jobs that implied traits such as submissiveness and warmth in the job description. However, maturefaced applicants were rated higher than babyfaced ones when the job description implied traits such as dominance, coldness, and shrewdness. In the only study that examined the link among babyfaceness, trustworthiness, and persuasion, Brownlow (1992) found that the babyfaced spokesperson produced more agreement with the message than the maturefaced spokesperson when the spokesperson was considered to be untrustworthy.

With the exception of the few studies discussed above, the focus of much of the babyface research has been on trait inferences and not on the downstream consequences of these inferences, such as evaluations and judgments (Zebrowitz 1997). In addition, while the finding that babyfaces evoke specific trait inferences is fairly robust, prior research has not systematically investigated the boundary conditions for this effect. Further, it is not clear whether these inferences are spontaneous and correctable in the face of competing contextual cues. Exactly how these inferences influence subsequent evaluations has also not been pinned down. Our research contributes to the literature by addressing these gaps. Examining boundary conditions as well as directly manipulating associations enables us to predict when facebased inferences of honesty and innocence influence subsequent judgments positively versus negatively or not at all. We elaborate on our contribution after discussing the context for our experiments.

We examine a situation where a company has a productrelated PR crisis because it has released a drug in the marketplace that later turns out to have negative side effects. This results in adverse publicity - a news report of the crisis, which includes a photograph of the CEO. Press articles including pictures of key players are common when such crises are first reported in the media, as in the Wal-Mart example discussed in our opening paragraph. A question that is very likely to arise in a reader's mind when reading a news item about the drug side-effects crisis is whether the company knew about the problem beforehand but did not acknowledge it publicly. One cue that might be used to answer the question of intentional deception might be the face of the CEO and how honest it looks. On the basis of the literature discussed above, we expect that a babyfaced CEO will be perceived as more honest and will produce more-favorable company attitudes than his more maturefaced counterpart. A babyfaced spokesperson who delivers an apology during a corporate PR crisis is likely to be judged to be more innocent of intentional harm than a maturefaced one; by extension, the company should not be held to account for the transgression.

Past literature on facial shape does not speak to the conditions under which this effect would hold. For example, if consumers are alerted to other cues in the situation that are more diagnostic regarding intentionality, appearance-based inferences are likely to be corrected (Gilbert 1989). One situational cue could be the severity of the crisis. As the severity of the crisis heightens-for example, a drug has side effects that affect a large number of users - the spontaneous inference that the babyfaced CEO did not intentionally mislead is likely to be "corrected," as long as cognitive capacity is available. The maturefaced or babyfaced CEO's credibility will be low in such a serious crisis situation, and attitudes toward the company will likely be negative regardless of the shape of the CEO's face.

Another gap in the literature concerns the lack of attention to the role of face-trait associations in downstream judgments. We address this issue experimentally through the prior priming of associations either consistent with the babyface stereotype or counter to it, thus offering triangulating evidence of the specific role of face-trait associations on CEO and company judgments. We also examine this issue by creating situations in which innocence has positive versus negative implications. While the greater innocence of a babyfaced person might be considered an advantage, the same association could backfire in situations where innocence is associated with naïveté. A person who is naive is less likely to be watchful, vigilant, and careful than a person who is not naive, and he or she may therefore be too trusting of others, even when such trust is not warranted. We take the same construct of innocence and the associations related to it to show how, in a PR crisis, perceptions of innocence arising from babyfaceness can be either an advantage (a situation where perceptions of a CEO's honesty is of primary importance) or a disadvantage (a situation where perceptions of a CEO being on guard/his or her watchfulness is of primary importance).

The four experiments described above make the following contributions. First, we demonstrate that trait inferences of honesty are drawn spontaneously from babyfaceness, even under constrained capacity conditions. This inference is corrected in the presence of situational evidence (e.g., a severe crisis) that renders it implausible; however, this correction occurs only if cognitive resources are available. The fact that these babyface-trait associations underlie evaluations is 
clearly demonstrated by reversing the effect of babyfaceness on judgments in two ways: (a) creating associations that are the opposite of the chronic association (babyfacenesshonesty/innocence), and $(b)$ creating a situation where innocence is a liability and, hence, babyfaceness has a downside. Male faces are used to examine these effects in our research since the babyface effect has been found to be more pronounced for male than for female faces (Zebrowitz 1997).

\section{EXPERIMENT 1: THE BABYFACE EFFECT AND BOUNDARY CONDITIONS}

This experiment tests the hypothesis that when the crisis is not very severe, babyfaced CEOs will be perceived as more credible than maturefaced CEOs, and attitudes toward the babyfaced (vs. maturefaced) CEO's company will be more favorable. This effect will diminish as crisis severity increases.

\section{Method}

The design is a 2 (face of CEO: babyface vs. mature face) $\times 3$ (severity of the crisis: low vs. medium vs. high) between-subjects design. The stimuli consist of a fictitious Yahoo! news article about a pharmaceutical company, Biomedic, whose new product, Coughless, has been found to have side effects (fig. 1). The article featured a photograph of the CEO, who was either babyfaced or maturefaced, and was titled "CEO Denies Knowledge of Side Effects."

A single photo was used and was morphed into both a babyface photo and a mature face photo with the use of FaceFilter Studio software (see fig. 2 for photos used). On the basis of the literature, we manipulated the eyes, eyebrows, and chin of the person in the photo to make two different versions (babyface vs. mature face).

A pilot study confirmed the difference in the perceived babyfaceness of the person in the two photos. Eighty-nine undergraduate students were randomly assigned to rate one of the two target photos plus several filler photos on several dimensions, using seven-point scales ranging from 1 (definitely no) to 7 (definitely yes). Two scales measured perceived babyfaceness; one assessed how babyfaced the person was, and the second assessed how maturefaced the person was. A difference score was computed on the basis of these two scales. Results revealed that the babyfaced person was perceived to have more of a babyface than the maturefaced person $(M$ 's $=-1.68$ vs. -2.62 , respectively; $F(1,87)=4.54, p<.05)$. Consistent with the literature, the babyface was seen as $\operatorname{kinder}(M$ 's $=4.70$ vs. $3.74 ; F(1,87)=14.95, p<.001)$, more honest $(M$ 's $=$ 4.30 vs. $3.45 ; F(1,87)=12.08, p<.001)$, and warmer $(M$ 's $=4.94$ vs. $3.71 ; F(1,87)=30.21, p<.001)$ than the mature face. There were no differences between the two faces in perceived age, expertise, and attractiveness.

Severity was manipulated by varying the percentage of users (1\% vs. $10 \%$ vs. $20 \%)$ who experienced side effects while using Coughless. This manipulation was pretested us- ing 24 participants who rated the seriousness of a number of different potential side effects on a seven-point scale. Participants rated the $1 \%$ case as significantly less serious than the $10 \%$ case $(M$ 's $=2.54$ vs. $4.00 ; F(1,23)=$ $58.82, p<.001)$ and the $10 \%$ case as significantly less serious than the $20 \%$ case $(M$ 's $=4.00$ vs. 4.83; $F(1,23)=38.26, p<.001)$.

Undergraduate students $(N=134)$ at a major university in Hong Kong participated in the experiment for course credit and were randomly assigned to the various conditions. They were told that the study examined people's ability to comprehend and evaluate online business articles. After reading the article, participants reported their attitude toward the company on three seven-point scales (from 1 to 7): badgood, unfavorable-favorable, and negative-positive ( $a=$ 0.94). The next measure (five seven-point scales) related to subjects' perceptions of the perceived honesty of the company's CEO: not credible-credible, not sincere-sincere, not honest-honest, not believable-believable, and not convincing-convincing $(a=0.90)$. Participants then responded to a seven-point manipulation check question ranging from 1 (he has a mature-looking face) to 7 (he has a babyface). This was followed by two seven-point scales related to expertise $(a=0.88)$ : (1) not very knowledgeable about business to very knowledgeable about business and (2) very inexperienced in business to very experienced in business. None of the effects on expertise were significant.

\section{Results}

The manipulation check confirmed the success of the babyfaceness manipulation. A 2 (babyfaceness) $\times 3$ (severity) ANOVA revealed only a main effect, with the babyfaced CEO rated higher on babyfaceness $(M=4.22)$ than the maturefaced CEO $(M=3.30 ; F(1,128)=22.90, p<$ $.001)$.

A $2 \times 3$ ANOVA on company attitudes revealed the expected significant interaction effect (see table 1; $F(2,128)=3.34, p<.05)$. The main effects of face and severity were both not significant. Contrasts showed that in the $1 \%$ condition, participants had more-favorable attitudes toward the company with a babyfaced CEO $(M=3.56)$ than toward the one with a maturefaced CEO $(M=2.92$; $F(1,128)=4.49, p<.05$; one-tailed $p$ levels are used for all contrasts reported in this article). This face effect did not significantly influence company attitudes in the $10 \%$ and $20 \%$ conditions.

The $2 \times 3$ ANOVA on perceived honesty revealed a marginally significant interaction effect (see table 1; $F(2,128)=2.49, p<.09)$. Both main effects were not significant. In the low severity ( $1 \%$ side effects) condition, contrasts showed that participants rated the babyfaced CEO as more honest than the maturefaced CEO $(M$ 's $=$ 3.55 vs. 2.89 , respectively; $F(1,128)=4.47, p<.05)$. An ANCOVA confirmed that perceptions of honesty mediated the effects of babyfaceness on company attitudes. The previously significant effect of babyfaceness on company attitudes was no longer significant when perceived honesty 
FIGURE 1

STIMULI USED IN EXPERIMENTS 1-3 (BABYFACED CEO-LOW SEVERITY CONDITION)

Yahoo! News
Wed Apr 20, 2005

\section{CEO Denies Knowledge of Side Effects}

Wed Apr 20, 8:23 AM ET

By Brendan Intindola

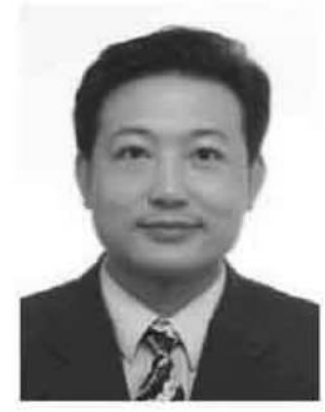

Henry Yip, CEO of Biomedic Ltd.

Hong Kong (Revters) - Henry Yip, The chief executive of the Hong Kong based pharmacy company, Biomedic Ltd., denied Tuesday that he knew beforehand that their new cold remedy, Coughless, which was launched on the market last month, causes headaches in some users.

When interviewed on Tuesday, Yip said, "When we introduced Coughless, I mentioned that our tests showed that Coughless was not just effective in reducing the symptoms of a cold; but that they also showed that there were no side effects. However, after competitors complained to the Consumer Council, we did some more tests. The results of these tests revealed that Coughless causes slight headaches in about $1 \%$ of users. I apologize for what happened."

was inserted as a covariate $(F(1,44)=0.88, p>.35$; for the covariate, $F(1,44)=16.64, p<.001)$. The mean square for the face effect was reduced $84 \%$.

The effect of having a babyface versus a mature face on perceived honesty was marginal in the $10 \%$ condition $(M$ 's $=3.68$ vs. 3.20 , respectively; $F(1,128)=2.30, p>$ $.06)$ and was not significant in the $20 \%$ condition. When the means within the babyfaced condition were compared, perceived honesty was not significantly different in the $1 \%$ versus the $10 \%$ condition, suggesting that inferences of honesty are drawn from a babyface unless strong situational evidence (e.g., $20 \%$ of users experienced side effects) renders this judgment implausible ("the company must have known").

\section{Discussion}

When only $1 \%$ of users are minimally adversely affected (e.g., by slight headaches), credibility of the denial of intentional wrongdoing is greater for the babyfaced CEO than for the maturefaced CEO. This appears to drive the morefavorable attitudes to the company. The news article in this 
FIGURE 2

FACES USED IN EXPERIMENTS 1-3
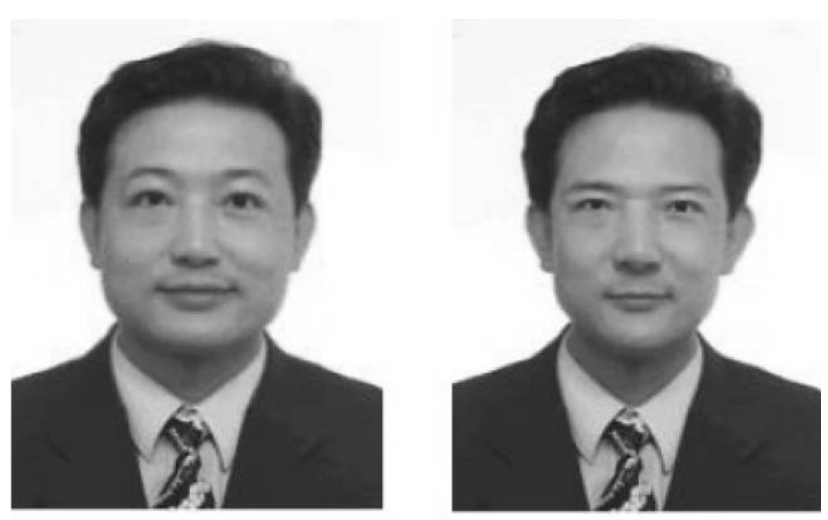

Babyface

Mature Face

experiment concerned denial of wrongdoing by the CEO; this presumably cued participants to think about the CEO's honesty. In the absence of other diagnostic cues to honesty, face shape influenced the formation of these judgments, which in turn influenced company attitudes. However, a more serious situation ( $10 \%$ of users getting slight headaches or, especially, $20 \%$ of users getting them) rendered a judgment of CEO honesty less plausible. Participants appeared to correct spontaneous inferences about the babyfaced CEO's honesty. Experiment 2 directly tests this posited mechanism of correcting spontaneous inferences of CEO trustworthiness.

\section{EXPERIMENT 2: SPONTANEOUS INFERENCE, DELIBERATE CORRECTION}

This experiment manipulates cognitive capacity and tests the hypothesis that the inference of trustworthiness is gen-

erated spontaneously on exposure to a babyfaced CEO. If this is the case, the inference and subsequent evaluation of the company should be more favorable when the CEO is babyfaced versus maturefaced under constrained capacity conditions, regardless of the severity of the crisis. However, when cognitive capacity is available, the initial babyfacetrustworthiness inference should be corrected when the crisis is severe, such that face has no effect on CEO and company evaluations.

\section{Method}

Undergraduate students $(N=194)$ at a major university in Hong Kong participated in the experiment for course credit and were randomly assigned to the cells of a 2 (face of CEO: babyface vs. mature face) $\times 2$ (severity of the crisis: low [1\%] vs. high [20\%]) $\times 2$ (cognitive load: low vs. high) between-subjects design. We predicted a three-way interaction, such that we replicate the two-way interaction between face and severity found in experiment 1 only in the low cognitive load condition. We expect a main effect of face in the high cognitive load condition where no correction for severity of crisis is expected.

Participants were given the same cover story as in study 1 and were told that an additional objective was to investigate people's numeric memory. To manipulate cognitive load, they were given either a seven-digit number (high load condition) or a one-digit number (low load condition) to remember and were told that they needed to recall the assigned number at the end of the experiment (Zemborain and Johar 2007).

Following these instructions, participants read the article and completed the same company attitude $(a=0.92)$ and perceived CEO honesty measures $(a=0.88)$ as in experiment 1. Participants were then asked to write down the number they were assigned to remember. They were also asked to recall the percentage of users who had experienced side effects according to the article that they had read. Finally, participants responded to the face manipulation check.

TABLE 1

RESULTS OF EXPERIMENT 1

\begin{tabular}{|c|c|c|c|}
\hline \multirow[b]{2}{*}{ Dependent variables } & \multicolumn{3}{|c|}{$\begin{array}{l}\text { Crisis severity (\% of users } \\
\text { getting headaches) }\end{array}$} \\
\hline & Low (1\%) & Medium (10\%) & High $(20 \%)$ \\
\hline \multicolumn{4}{|c|}{ Attitude toward the company: ${ }^{a}$} \\
\hline Babyface & $3.56(.88)$ & $3.43(1.04)$ & $2.70(.94)$ \\
\hline Mature face & $2.92(1.19)$ & $2.96(1.14)$ & $3.12(.73)$ \\
\hline \multicolumn{4}{|c|}{ CEO's perceived honesty:b } \\
\hline Babyface & $3.55(1.04)$ & $3.68(1.35)$ & $2.82(1.09)$ \\
\hline Mature face & $2.89(.98)$ & $3.20(.94)$ & $3.13(.98)$ \\
\hline \multicolumn{4}{|c|}{$\begin{array}{l}\text { NOTE.-Values are given as means (standard deviations). } \\
\text { aAttitudes were assessed with three seven-point scales (bad-good, unfavorable-fa- } \\
\text { vorable, negative-positive), which were averaged. } \\
\text { 'The CEO's perceived honesty was measured by five seven-point scales (not credi- } \\
\text { ble-credible, not sincere-sincere, not honest-honest, not believable-believable, not } \\
\text { convincing-convincing). }\end{array}$} \\
\hline
\end{tabular}


TABLE 2

RESULTS OF EXPERIMENT 2

\begin{tabular}{|c|c|c|c|c|}
\hline \multirow[b]{3}{*}{ Dependent variables } & \multicolumn{4}{|c|}{ Crisis severity (\% of users getting headaches) } \\
\hline & \multicolumn{2}{|c|}{ Low cognitive load } & \multicolumn{2}{|c|}{ High cognitive load } \\
\hline & Low $(1 \%)$ & High $(20 \%)$ & Low $(1 \%)$ & High $(20 \%)$ \\
\hline \multicolumn{5}{|c|}{ Attitude toward the company: ${ }^{a}$} \\
\hline Babyface & $3.71(.98)$ & $2.92(.95)$ & $3.64(.74)$ & $3.76(1.00)$ \\
\hline Mature face & $3.07(.96)$ & 3.08 (1.33) & $3.18(.81)$ & $2.96(.76)$ \\
\hline \multicolumn{5}{|c|}{ CEO's perceived honesty: } \\
\hline Babyface & $3.55(1.02)$ & $3.19(1.03)$ & $3.72(.91)$ & $3.72(1.02)$ \\
\hline Mature face & $3.13(.86)$ & $3.35(1.00)$ & $3.22(.75)$ & $3.29(.99)$ \\
\hline
\end{tabular}

\section{Results}

A $2 \times 2 \times 2$ ANOVA on babyfaceness revealed only the expected main effect $\left(M_{\text {baby }}=3.96\right.$ vs. $M_{\text {mature }}=3.53$; $F(1,186)=4.28, p<.05)$. Memory of the assigned number, as measured by recall, was high and was similar across conditions $\left(M_{\text {accuracy }}>93 \%\right)$. Results reported below cannot be explained by a lack of attention to severity of the crisis among those in the high cognitive load conditions. Participants accurately recalled the percentage of users who experienced side effects in both high load $\left(M_{\text {accuracy }}=85 \%\right)$ and low load $\left(M_{\text {accuracy }}=91 \%\right)$ conditions. Chi-square tests on the $2 \times 2 \times 2$ design revealed neither interaction nor main effects. The ANOVA results below remain unchanged when participants who did not recall side effects correctly are dropped from the analyses.

A $2 \times 2 \times 2$ ANOVA on company attitudes revealed the expected significant three-way interaction effect (see table $2 ; F(1,186)=4.38, p<.05)$. Further, participants had more-favorable attitudes toward the company with the babyfaced CEO $(M=3.51)$ than the one with the maturefaced CEO $(M=3.07 ; F(1,186)=10.05, p<.01)$. The other two main effects and all two-way interactions were not significant.

In the low cognitive load condition, the two-way interaction between face and crisis severity found in experiment 1 was replicated $(F(1,186)=4.23, p<.05)$. Participants had more-favorable attitudes toward the babyfaced CEO's company than the maturefaced CEO's company in the $1 \%$ condition $(M$ 's $=3.71$ vs. $3.07 ; F(1,186)=5.21, p<$ $.05)$. In the $20 \%$ condition, the face effect was not significant. Under high cognitive load conditions, only the main effect of face was significant $\left(M_{\text {baby }}=3.70\right.$ vs. $M_{\text {mature }}=$ 3.07; $F(1,186)=10.74, p<.001)$.

A $2 \times 2 \times 2$ ANOVA on perceived honesty revealed a similar pattern. Although the three-way interaction was not significant $(F(1,186)=0.88, p>.35)$, participants rated the babyfaced CEO as more honest $(M=3.55)$ than the maturefaced CEO $(M=3.24 ; F(1,186)=4.82, p<.05)$. The main effects of cognitive load and severity were not significant. Examining the low cognitive load conditions only, the two-way interaction between face and crisis severity was not significant $(F(1,186)=2.23, p<.13)$. Despite this, a contrast revealed that participants rated the babyfaced CEO as more honest than the maturefaced CEO in the $1 \%$ condition, although the effect was only marginal $(M$ 's $=3.55$ vs. $3.13 ; F(1,186)=2.16, p<.08)$, but not in the $20 \%$ condition $(p>.55)$. An ANCOVA confirmed the mediational role of honesty in the relationship between face and company attitudes. The previously significant effect of babyfaceness on company attitudes in the $1 \%$ condition was no longer significant when perceived honesty was inserted as a covariate $(F(1,185)=2.58, p>.05$; for the covariate, $F(1,185)=19.02, p<.001)$. The mean square for the face effect was reduced $65 \%$.

In the high cognitive load condition, only the main effect of face on honesty was significant $\left(M_{\text {baby }}=3.72\right.$ vs. $\left.M_{\text {mature }}=3.25 ; F(1,186)=6.00, p<.05\right)$. The effect of babyfaceness on company attitudes was attenuated, but still significant, when perceived honesty was inserted as a covariate $(F(1,185)=4.77, p<.03$; for the covariate, $F(1,185)=14.37, p<.001)$. The mean square for the face effect was reduced $56 \%$.

\section{Discussion}

Results reveal that babyface-honesty inferences occur under limited cognitive capacity, even in high crisis situations, and hence establish that babyface-honesty inferences are spontaneous. Further, these inferences are corrected when cognitive capacity is available. Inferences of CEO honesty mediate the effects of babyfaceness on company evaluations. In experiments 1 and 2, evidence that trait inferences underlie company evaluations is based on mediation analyses and hence is correlational. Experiment 3 manipulates the face-honesty association experimentally and helps pin down its role in the face-company evaluation relationship. 


\section{EXPERIMENT 3: REVERSING THE BABYFACE EFFECT}

Given the default association of babyfaceness with honesty, any transgression on the part of a babyfaced individual is likely to be seen as unplanned and unintentional; dishonesty by contrast would represent a (deliberate) intention to deceive (Sengupta, Dahl, and Gorn 2002). If the natural association between babyface and unintentional wrongdoing is reversed by creating associations between babyfaceness and intentional harm, then the positive effect of babyfaceness on company attitudes found in experiments 1 and 2 should diminish or even reverse. Priming participants with the association of the babyfaced person doing intentional harm and the maturefaced person doing unintentional harm should result in similar or more-favorable attitudes for the maturefaced CEO versus the babyfaced CEO. However, priming participants with the more natural association of the babyfaced person doing wrong unintentionally and the maturefaced person doing wrong intentionally should replicate the attitude results found in experiment 1 and in the low cognitive load conditions of experiment 2 .

\section{Method}

Undergraduate students $(N=111)$ were randomly assigned to one of the cells in the 2 (association conditions: face type consistent association vs. face type inconsistent association) $\times 2$ (face: babyface vs. mature face) betweensubjects design. Participants were told that they would be taking part in several unrelated studies and completed some studies before they performed the association task study, followed by the Web article (used in experiments 1 and 2) study. To manipulate associations between face and intentionality, participants were given a questionnaire that was purportedly a memory test. It contained pictures of six different anonymous "criminals" accompanied by a one-sentence description of each of their offenses. To select the pictures, pretest participants $(N=137$ in total) were shown several different male faces and were asked to rate them on babyfaceness on a seven-point scale ( $1=$ definitely no, $7=$ definitely yes). Three babyface pictures $(M=3.48)$ and three mature face pictures $(M=2.45)$ were selected for use in the association task $(F(1,135)=14.95, p<$ $.001)$.

A variety of pretests were done to select the intentional and unintentional offenses. In the final one, 22 undergraduate students were shown a list of different offenses, each described in one sentence, and rated the intentionality of the offense on a scale from 1 (not at all intentional) to 10 (very intentional). Three "high intention" offenses (e.g., driving at 150 kilometers per hour in a 30-kilometer-per-hour speed zone) and three "low intention" offenses (e.g., driving at 96 kilometers per hour in a 90-kilometer-per-hour speed zone) were selected for use in the association task ( $M$ 's $=8.32$ vs. 4.68, respectively; within-subjects, $F(1,21)=43.78$, $p<.001$ ). In the consistent (inconsistent) priming condition, three highly (less) intentional offenses were paired with three mature faces, and three less (highly) intentional offenses were paired with three babyfaces (see fig. 3).

In the main study, participants were given 5 minutes to memorize the pictures of the people and their offenses. Then after a 3-minute break, they were asked to match the picture of the criminal with the described offense. (Only two people made any mistakes, one in each condition.) After this "memory study" (actually the association task), participants did exactly the same task as in the least serious (1\% side effects) condition in experiment 1 . They then responded to the same dependent variables as in experiment 1 , along with three additional measures related to intention to deceive $(1=$ very unlikely, $7=$ very likely; $a=0.71$ ): (1) whether or not the CEO knew that the drug could cause headaches in some users before it was put on the market, (2) whether he felt guilty about what he did (reversed scored), and (3) whether he was trying to cheat customers. The photos were also rated on perceived attractiveness $(1=$ not attractive at all, $7=$ very attractive). Finally, participants responded to a funnel debriefing questionnaire that probed for awareness or suspicion concerning the association manipulation (Chartrand and Bargh 1996). There was no indication that any of the participants knew that the studies concerned the effect of face shape. Also, none of the participants reported that they thought there were links between these two studies.

\section{Results}

A $2 \times 2$ ANOVA on perceived babyfaceness revealed only a significant main effect for face $\left(M_{\text {baby }}=4.13\right.$ vs. $\left.M_{\text {mature }}=3.47 ; F(1,107)=9.27, p<.01\right)$, confirming the success of the manipulation.

A $2 \times 2$ ANOVA on company attitudes $(a=0.95)$ revealed a significant interaction effect (see table 3; $F(1,107)=7.24, p<.01)$. No other effects were significant. In the condition where consistent face type associations were primed, attitudes were more favorable toward the company with the babyfaced CEO than with the maturefaced $\mathrm{CEO}$, as in experiment 1 and the low load condition of experiment 2 ( $M$ 's $=3.54$ vs. 3.07; $F(1,107)=3.16$, $p<.05)$. When participants were primed with inconsistent associations, attitudes were less favorable toward the company with the babyfaced CEO than with the maturefaced CEO $(M$ 's $=2.72$ vs. 3.28; $F(1,107)=4.10, p<.05)$. This reversal in the pattern of attitudes provides strong evidence of our proposition that the association between face shape and honesty/unintentionality underlies the effect of face on attitudes.

The pattern of results for perceived honesty $(a=0.91)$ was the same as that for company attitudes. A $2 \times 2$ ANOVA revealed a significant interaction effect $(F(1,107)=9.13$, $p<.01)$. Participants primed with consistent associations perceived the babyfaced CEO as more honest than the maturefaced CEO ( $M$ 's $=3.58$ vs. 2.86; $F(1,107)=5.62$, $p<.01)$. Participants primed with inconsistent associations, however, perceived the babyfaced CEO to be less honest $(M ' s=2.90$ vs. $3.52 ; F(1,107)=3.66, p<.05)$.

The interaction effect of face type and association con- 
FIGURE 3

ASSOCIATION MATERIALS USED IN EXPERIMENT 3 (CONSISTENT ASSOCIATION CONDITION)

\section{Crime Sensitivity Questionnaire}

The Social Science Division is conducting a research project about undergraduate students' knowledge of crimes and illegal activities in Hong Kong. We'd like to collect some preliminary data.

We will give you 5 minutes to look at the people below and the crimes they committed. Later we will test whether you can remember which people committed which crime.

1)

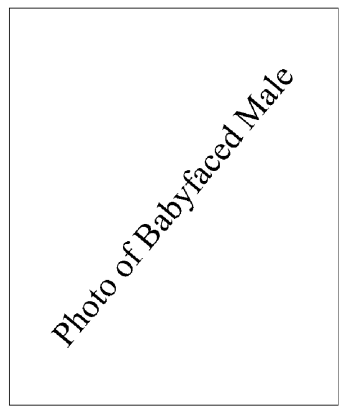

Fraud

欺詐

He forgot to put some of the salary he earned on his income tax form.

4)

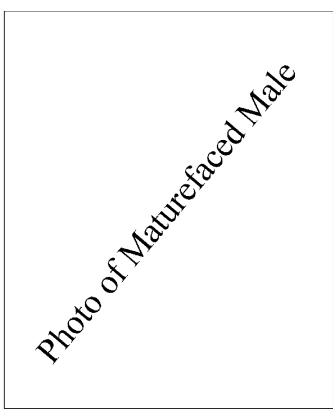

Fraud

欺詐

He created a new company to hide some of his existing company's losses.
2)

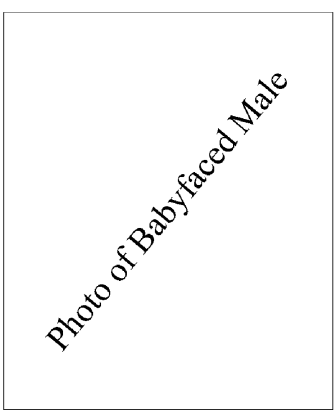

Injure others

傷人

He jumped out and surprised his little brother, which made his brother fall down the stairs and hurt himself.

5)

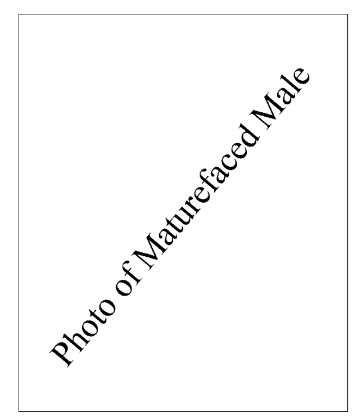

Injure others

傷人

To take revenge on his former boss, he tracked him back home and injured him.
3)

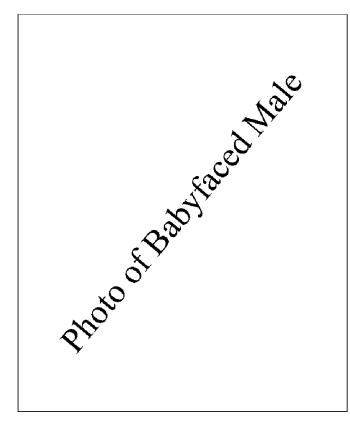

Speeding

超速駕駛

He drove 96 kilometers on a road with a 90 kilometer per hour speed limit.

6)

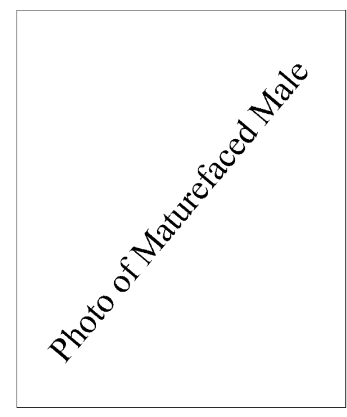

Speeding

超速駕駛

He drove 150 kilometers on a road with a 30

kilometer per hour speed limit. 
TABLE 3

RESULTS OF EXPERIMENT 3

\begin{tabular}{|c|c|c|}
\hline \multirow[b]{2}{*}{ Dependent variables } & \multicolumn{2}{|c|}{ Priming conditions } \\
\hline & $\begin{array}{c}\text { Consistent association } \\
\text { (baby-unintentional harm } \\
\text { and mature-intentional } \\
\text { harm) }\end{array}$ & $\begin{array}{c}\text { Inconsistent association } \\
\text { (baby-intentional harm } \\
\text { and mature-unintentional } \\
\text { harm) }\end{array}$ \\
\hline \multicolumn{3}{|c|}{ Attitude toward the company: ${ }^{a}$} \\
\hline Babyface & $3.54(1.16)$ & $2.72(.62)$ \\
\hline Mature face & $3.07(.79)$ & $3.28(1.20)$ \\
\hline \multicolumn{3}{|l|}{ Perceived honesty: ${ }^{b}$} \\
\hline Babyface & $3.58(1.08)$ & $2.90(1.17)$ \\
\hline Mature face & $2.86(1.03)$ & $3.52(1.03)$ \\
\hline \multicolumn{3}{|l|}{ Intention to deceive: } \\
\hline Babyface & $4.20(1.21)$ & $4.57(.73)$ \\
\hline Mature face & $4.79(1.09)$ & $4.34(1.07)$ \\
\hline \multicolumn{3}{|c|}{$\begin{array}{l}\text { NOTE.-Values are given as means (standard deviations). } \\
\text { aAttitudes were assessed with three seven-point scales (bad-good, unfavorable-favorable, negative- } \\
\text { positive), which were averaged. } \\
\text { bThe CEO's perceived honesty was measured by five seven-point scales (not credible-credible, not } \\
\text { sincere-sincere, not honest-honest, not believable-believable, not convincing-convincing). } \\
\text { 'The CEO's intention to deceive was measured by three seven-point scales: (1) whether or not the } \\
\text { CEO knew that the drug could cause headaches in some users before it was put on the market, ( } 2 \text { ) } \\
\text { whether he felt guilty about what he did (reversed scored), and (3) whether he was trying to cheat customers } \\
\text { (1 = very unlikely, } 7 \text { = very likely). }\end{array}$} \\
\hline
\end{tabular}

sistency on company evaluations was no longer significant when perceived honesty was included as a covariate $(F(1,106)=1.41, p>.23)$. The $F$-value for the covariate was significant as well $(F(1,106)=45.03, p<.001)$. When the consistent and inconsistent association groups were looked at separately, the ANCOVA results revealed that face type was no longer significant in both the consistent association group $(F(1,54)=0.31, p>.20)$ and the inconsistent association group $(F(1,51)=1.27, p>.10)$. The mean squares for the effect of face type on company attitudes were reduced $93 \%$ and $79 \%$ in the consistent association and inconsistent association groups, respectively. The covariate was significant in both the consistent association group $(F(1,54)=21.19, p<.001)$ and the inconsistent association group $(F(1,51)=23.52, p<.001)$.

Additional support for the mediating role of inferences regarding honesty comes from the findings on the intentionto-deceive measure, which revealed a significant interaction effect of association consistency and face $(F(1,107)=$ $4.03, p<.05)$. Participants primed with consistent associations rated the babyfaced CEO as having less of an intention to deceive than the maturefaced CEO $(M$ 's $=4.20$ vs. 4.79; $F(1,107)=4.43, p<.05)$. Participants primed with inconsistent associations did not differ in their intention ratings for babyfaced versus maturefaced CEOs.

\section{Discussion}

Results of this experiment demonstrate that natural associations between babyfaceness and honesty/unintentional wrongdoing underlie inferences about perceived honesty and, hence, persuasion. We replicate the results of experiment 1 when we prime the natural associations of baby- faceness-unintentional wrongdoing and maturefacenessintentional wrongdoing and reverse the results when we create the opposite associations. One could argue that intentionality of the offense was confounded with offense severity in the priming phase. Nevertheless, it is hard to see how severity could account for the pattern of results obtained, given that crisis severity was held to be low, at $1 \%$ side effects in the main experiment. The results for honesty provide reassurance regarding the role of intentions.

The findings in the reverse-association condition are especially powerful considering that different faces were used in the association task and in the main experiment. Results from the funnel debriefing reveal that participants were not consciously aware that the association task and the company attitude questionnaire were related and did not realize that the study was about face shape.

To further examine whether the associations between face shape and honesty are consciously accessible to participants, 15 participants were exposed to the consistent association task, and 15 participants were exposed to the inconsistent association task. After they had matched the faces with the offenses, participants were asked to look at the sheet with the photos and the offenses again and to write down the purpose of the recognition study. None of the participants wrote down anything about face shape or whether or not the associations between faces and offenses were natural. All associations were perceived to be plausible; yet the default associations, as numerous studies have shown, are of babyface and honesty. These results support the notion that links between babyfaceness and honesty are completely unconscious.

In most priming studies, participants are primed with existing material in memory. In experiment 3 , the inconsistent 
condition went beyond mere priming and created new associations in memory that were the opposite of associations that participants had stored in memory. Our results are particularly striking given the potential barriers involved in reversing associations in existing memory. Experiment 4 uses a different task to once again demonstrate that honestyrelated associations with babyfaceness drive judgments.

\section{EXPERIMENT 4: THE DOWNSIDE OF BABYFACENESS}

Experiment 4 was conducted to show that the association of babyface and innocence might have negative consequences during a PR crisis if innocence implies naïveté. Innocent individuals may not themselves intentionally do harm, but they may be prone to being taken advantage of because they do not suspect others of doing harm. We use this insight to design experiment 4 , where we construct a situation in which a company recovering from a PR crisis is searching for a new CEO. We expect that a maturefaced new CEO will be viewed as a better choice to lead the company than a babyfaced CEO in the vigilance-in-doubt scenario, whereas a babyfaced CEO will be viewed as a better choice than the maturefaced CEO in the honesty-indoubt scenario.

\section{Method}

Undergraduate students $(N=98)$ at a large Hong Kong university participated in the study for course credit and were randomly assigned to cells in a 2 (face: babyface vs. mature face) $\times 2$ (scenario: honesty in doubt vs. vigilance in doubt) between-subjects design. To test the robustness of the babyface effects we found previously, we used a different pair of faces in experiment 4. As in the earlier experiments, a photo was taken from the Internet and was morphed into a babyfaced version and a maturefaced version (see fig. 4). Using the same scales and procedure as in the faces pretest in experiment 1 , a pilot study $(N=89)$ confirmed the difference in the perceived babyfaceness of the person in the two photos $(M$ 's $=1.06$ vs. -1.74 ; $F(1,87)=37.98, p<.001)$. Consistent with the babyface stereotype, the person in the babyfaced (vs. maturefaced) photo was also perceived to be kinder ( $M$ 's $=4.17$ vs. 2.93; $F(1,87)=22.99, p<.001)$, more honest $(M$ 's $=$ 4.34 vs. $3.36 ; F(1,87)=3.82, p<.06)$, and warmer $(M$ 's $=3.43$ vs. $2.55 ; F(1,87)=11.63, p<.001)$. Perceived expertise did not differ.

The procedure was the same as in the previous experiments. The article was different in this case and was titled "Biomedic appoints new CEO." The fictitious Yahoo! news page contained both the article and a photo of the new CEO (babyface or mature face across conditions). The content of the article was manipulated to create two versions, an honesty-in-doubt version and a vigilance-in-doubt version (see the appendix). The honesty-in-doubt scenario focused on the former CEO intentionally deceiving the company's customers; if babyfaces are associated with honesty, participants
FIGURE 4

FACES USED IN EXPERIMENT 4
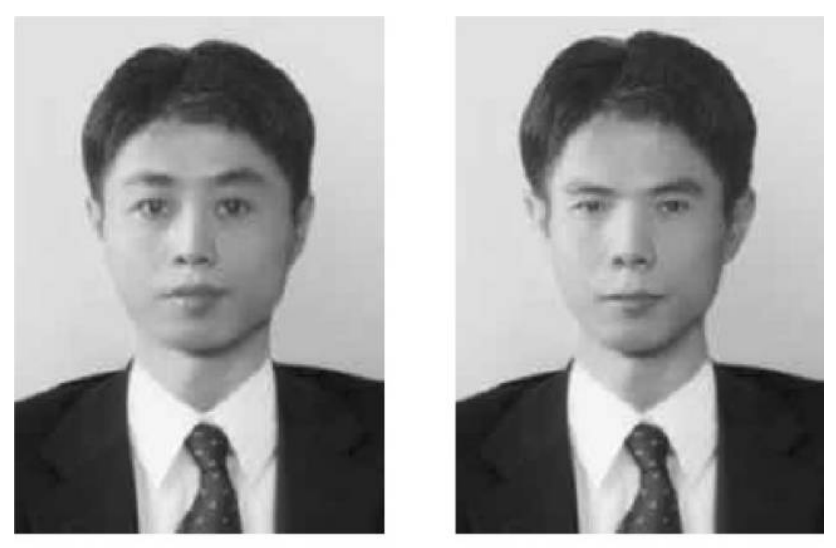

Babyface

should be more likely to prefer the babyfaced new CEO in this condition. The vigilance-in-doubt scenario focused on the naïvete of the former CEO; participants should be more likely to prefer the maturefaced new CEO in this condition. After reading the article, participants were asked whether the new CEO was a good choice and whether the board had picked the right CEO given the company's current situation. They responded on eight-point scales $(1=$ very unlikely, $8=$ very likely; $a=0.83$ ). Pretesting had revealed that, without any information about the characteristics or behavior of the new CEO, participants just checked off the midpoint if given the opportunity to do so. We used eight-point scales without a midpoint in this study to increase the sensitivity of the measures.

Participants then rated the likelihood of the new CEO being honest and vigilant, each on three scales; honesty and vigilance measures were counterbalanced across subjects. The honesty questions assessed the extent to which the new CEO would be honest with customers and not mislead them if a drug in fact had side effects, and whether he could be trusted ( $1=$ very unlikely, $8=$ very likely; $a=0.92)$. The vigilance questions assessed the extent to which he would check the reports from the company scientists very carefully, always be on his guard, and think everything through before he made a decision $(a=0.88)$. Next, participants responded to questions concerning their attitude toward the company ( $a=0.94$ ). Finally, they rated the perceived babyfaceness of the CEO and his attractiveness, intelligence, and knowledge.

\section{Results}

As confirmation of the success of the manipulation, a 2 (face: baby vs. mature) $\times 2$ (scenario: honesty in doubt vs. vigilance in doubt) ANOVA on babyfaceness revealed a significant main effect of face $\left(M^{\prime}\right.$ 's $=5.57$ vs. 3.69; 
$F(1,94)=42.26, p<.001)$. There were no differences between the babyfaced versus maturefaced new CEO in attitude toward the company, perceived intelligence, perceived attractiveness, and perceived knowledge. A posttest $(N=$ 30) showed that the babyfaced CEO was perceived to be slightly, but not significantly, younger (mean age 36.67 years) than the maturefaced CEO (mean age 38.80 years; $F<1)$.

The key dependent variable was the evaluation of the new CEO. A $2 \times 2$ ANOVA revealed a significant interaction effect (see table $4 ; F(1,94)=7.18, p<.01$ ) but no significant main effect for either face or scenario. As expected, contrasts showed that participants in the honesty-indoubt condition evaluated the babyfaced CEO more favorably $(M=4.87)$ than the maturefaced CEO $(M=4.21$; $F(1,94)=4.07, p<.05)$. In the vigilance-in-doubt scenario, participants evaluated the babyfaced CEO less favorably than the maturefaced $\mathrm{CEO}(M$ 's $=3.83$ vs. 4.40; $F(1,94)=3.14, p<.05)$.

An ANOVA on perceived honesty revealed only a significant main effect of scenario $(F(1,94)=4.71, p<$ $.05)$. The honesty ratings of the new CEO were higher in the honesty-in-doubt condition $(M=5.43)$ than in the vigilance-in-doubt condition $(M=4.46 ; \quad F(1,94)=4.71$, $p<.05)$. Despite the lack of a significant interaction $(F(1,94)=2.41, p>.15)$, participants in the honesty-indoubt condition perceived the babyfaced CEO as being more honest $(M=5.42)$ than the maturefaced one $(M=4.69$; $F(1,94)=3.43, p<.05)$. In the vigilance-in-doubt condition, perceptions of honesty were virtually identical for the new babyfaced and maturefaced CEO ( $M$ 's $=4.42$ vs. 4.49; $F<1)$.

An ANOVA on perceived vigilance revealed a significant main effect of scenario $\left(M_{\text {hon.-doubt }}=5.86\right.$ vs. $M_{\text {vigil.-doubt }}=$ 4.88; $F(1,94)=17.14, p<.001)$. There was a significant face effect $(F(1,94)=4.95, p<.05)$. The maturefaced CEO was rated as more vigilant $(M=5.62)$ than the babyfaced one $(M=5.09)$. The interaction was not significant $(F<1)$. A contrast nevertheless showed that participants in the vigilance-in-doubt condition rated the maturefaced CEO as more vigilant $(M=5.19)$ than the babyfaced CEO $(M=4.52 ; F(1,94)=3.84, p<.05)$. In the honesty-indoubt condition, there was no difference in the vigilance ratings of the babyfaced $\mathrm{CEO}$ and the maturefaced CEO.

Mediation tests were done in both the honesty-in-doubt and vigilance-in-doubt conditions to test if perceived honesty and perceived vigilance, respectively, mediated the effect of the new CEO's face shape on evaluations of the new CEO. When perceived honesty was inserted as a covariate in the honesty-in-doubt condition, the previously significant face effect was no longer significant $(F(1,46)=2.23, p>$ .14). The $F$ for the covariate was significant $(F(1,46)=$ $5.52, p<.05)$. The mean square for the face effect was reduced $51 \%$. When perceived vigilance was inserted as a covariate in the vigilance-in-doubt condition, the previously significant face effect was no longer significant $(F(1,46)=0.48, p>.49)$. The $F$ for the covariate was sig-
TABLE 4

RESULTS OF EXPERIMENT 4

\begin{tabular}{|c|c|c|}
\hline \multirow[b]{2}{*}{ Dependent variables } & \multicolumn{2}{|c|}{ Scenario } \\
\hline & $\begin{array}{l}\text { Honesty } \\
\text { in doubt }\end{array}$ & $\begin{array}{l}\text { Vigilance } \\
\text { in doubt }\end{array}$ \\
\hline \multicolumn{3}{|c|}{ Evaluation of CEO choice:a } \\
\hline Babyface & $4.87(1.08)$ & $3.83(1.21)$ \\
\hline Matur & $21(1.16)$ & 4.4 \\
\hline \multicolumn{3}{|l|}{ Honesty measures: ${ }^{b}$} \\
\hline Babyface & $42(1.57)$ & 4.4 \\
\hline Matu & & \\
\hline \multicolumn{3}{|l|}{ Vigilance measures: ${ }^{c}$} \\
\hline Babyface & $5.65(1.29)$ & $4.52(1.41)$ \\
\hline Mat & $(.93)$ & 5. \\
\hline \multicolumn{3}{|c|}{ Attitude toward the company: } \\
\hline Babyface & $(1.04)$ & 3.3 \\
\hline Mature face & $3.68(1.05)$ & 3.45 \\
\hline \multicolumn{3}{|c|}{$\begin{array}{l}\text { NOTE.-Values are given as means (standard deviations). } \\
\text { a'Evaluation of CEO choice was assessed with two eight-point } \\
\text { scales: ( } 1 \text { ) whether the new CEO was a good choice and (2) whether } \\
\text { the board had picked the right CEO given the company's current } \\
\text { situation }(1=\text { very unlikely, } 8=\text { very likely). } \\
\text { berceived honesty was measured by three eight-point scales: (1) } \\
\text { whether the new CEO would be honest with customers, (2) whether } \\
\text { he would not mislead customers if a drug in fact had side effects, } \\
\text { and ( } 3 \text {, whether he could be trusted ( } 1=\text { very unlikely, } 8 \text { = very } \\
\text { likely). } \\
\text { "Perceived vigilance was measured by three eight-point scales: (1) } \\
\text { whether the new CEO would check the reports from the company } \\
\text { scientists very carefully, (2) whether he would always be on his guard, } \\
\text { and (3) whether he would think everything through before he made } \\
\text { a decision ( } 1=\text { very unlikely, } 8=\text { very likely). } \\
\text { dAttitudes were assessed with three seven-point scales (bad-good, } \\
\text { unfavorable-favorable, negative-positive), which were averaged. }\end{array}$} \\
\hline
\end{tabular}

nificant $(F(1,46)=31.34, p<.001)$. The mean square for the face effect was reduced $91 \%$. Additional analyses showed that the face effects on the evaluation of the new CEO were not diminished when vigilance was used as the covariate in the honesty-in-doubt condition $(F(1,46)=$ $5.60, p<.05)$ or when honesty was used as the covariate in the vigilance-in-doubt condition $(F(1,46)=4.20, p<$ $.05)$. These results argue against a sheer carry-over explanation for the similar findings on the dependent variable and the mediator.

\section{Discussion}

These results provide further evidence that the traits associated with babyfaceness are used in judgments. This time it was judgments related to CEO choice rather than company attitudes. In contexts where innocence has positive implications, a babyface is evaluated more favorably. However, in contexts where innocence conveys naïveté, a mature face is evaluated more favorably. Not all positive traits are equally desirable in all situations; for example, in an honesty-in-doubt situation, honesty mediates judgments of a prospective CEO. In the vigilance-in-doubt situation, vigilance mediates judgments. 


\section{GENERAL DISCUSSION}

Our research suggests that in PR crises the face of the company matters. In four experiments, we find that what might be considered surface characteristics, such as the babyfaceness of a CEO, affect consumer judgments. This particular facial characteristic affects the perception of a CEO's honesty/innocence and, hence, the credibility of the denial of wrongdoing. Perceived credibility in turn affects attitudes toward the company. Associations of honesty and innocence with babyfaceness also affect judgments of trustworthiness and vigilance.

Our experiments concerned a product-related PR crisis. The marketing literature has focused on "what" to say in a crisis situation (Ahluwalia, Burnkrant, and Unnava 2000) and on attributions made from prior company evaluations (Johar 1996). However, research has not had much to say on the more "superficial" aspects of the response, such as the face of the spokesperson. In experiments 1 and 2, we demonstrate that when the company's honesty is in doubt and cues regarding intentions are absent, consumers are likely to infer whether the company intended harm from the face of the spokesperson. Consistent with the babyface literature, we find that consumers are likely to infer that babyfaced CEOs have a lower intention to deceive than maturefaced CEOs. However, situational cues, such as severe crises that render this inference implausible, are used to correct for the spontaneous inference of lower intentionality if cognitive resources are available to facilitate this correction. If sufficient capacity is not available, consumers will not make this correction, supporting our position that the intentionality inference based on babyfaceness is spontaneous. It is possible that severe crises reduce cognitive capacity by drawing consumers' cognitive resources away, toward the crisis, suggesting that corrections for the babyface effect may not occur in the real world in severe crisis situations.

Experiment 3 provides experimental support for the facehonesty association playing a critical role in driving company evaluations. What is truly striking is that newly created associations of babyface-intentional guilt resulted in the babyfaced CEO being seen as less trustworthy and his company being judged less favorably as a result. Experiment 4 provided further evidence for the underlying associational mechanism. Even more important, it demonstrated that the characteristic of innocence associated with babyfaces can have a potential downside. When a past CEO was suspected of harming the company by a lack of vigilance, the maturefaced CEO was the preferred choice for the new CEO. As expected, when a past CEO was suspected of being less than honest, the babyfaced CEO was the preferred choice for the new CEO.

These results add to a growing body of research on the mediational effects of inference making in the consumer behavior literature (e.g., Johar, Sengupta, and Aaker 2005) and establish that spontaneous inferences regarding personality often drive judgments. The results of our research have implications for any consumer situation where there are trustworthiness and/or vigilance concerns and multiple play- ers. There are instances in negotiations and sales, for example, where consumers must evaluate the trustworthiness of several players. Salespeople frequently try to appear as if they are acting as the consumers' advocate, trying to get the best terms from a manager of the business. Since this social theater requires the belief in a manager who is holding back information and a salesperson who is transparent, potentially the worst terms for consumers may result when the salesperson has a babyface and the manager's face is mature.

One feature of our research is that the insight we provide into underlying processes is done through the use of different operational procedures and different dependent and mediating variables. A limitation of our findings must be acknowledged. Across our experiments, the movements on the dependent variables of interest occur mostly in the babyface conditions. One could argue that severity of the crisis should decrease company evaluations regardless of the CEO's face; however, this does not happen in the maturefaced condition. One explanation for this lack of movement could be a floor effect, such that company evaluations are low in crisis situations (regardless of crisis severity) when the CEO's face meets expectations (i.e., when it is mature). This could be the default evaluation of a company in crisis.

Our research speaks to the general issue of automaticity and thin-slice judgments. The process that underlies subjects' attitudes toward the company is undoubtedly a deliberative one. These attitudes are derivative and are based on a conscious consideration of the attributes of the $\mathrm{CEO}$ - attributes like trustworthiness and vigilance, whichever of the two is salient in the particular PR crisis the company faces. While company attitudes may reflect a deliberative consideration of trustworthiness or wariness, the link between judgments of these attributes and babyfaceness of the CEO appears to be automatic.

From a broader perspective, it has been argued that a person's nonverbal behaviors (facial expressions, gestures, movements, tone of voice, and so on) give a truer picture of what they are really like than their verbal behavior does (see Gladwell [2005] for discussions of this research). The answer might lie in nonverbal behaviors being less controllable than verbal behaviors and thus more indicative of what people are really like. Nonverbal behaviors are, however, just one type of nonverbal cue (Gilbert and Krull 1988). The physical characteristics of the person also offer nonverbal cues that may be taken into account. Take the person's face and the particular characteristic we focus on in this research-whether the person's face has a babyfaced shape or a maturefaced shape. It may be given undue weight in interpersonal judgments because of the consistent, redundant, and fixed feedback it provides, feedback that may be especially difficult to ignore since the observer will typically be unaware of its biasing influence. Ironically, the unchanging and uncontrollable aspects of these characteristics may increase confidence in judgments.

From the practical standpoint, a company has many issues to consider when it is faced with a PR problem and how to respond to it. Our research might be capable of informing 
it about one specific aspect regarding its response-the face of the person it sends out to publicly address the problem. We believe that not putting a face on the crisis is not an option because the media are likely to feature someone from the company in their reports of the PR crisis. Recognizing this, the company can control whose face is put on the crisis. When coupled with a long history of research in psychology, our research suggests that the face shape of this person is not a trivial consideration. It suggests that understanding the nature of the crisis is the key to ensuring more-favorable outcomes. Is the consumer likely to consider the problem that gave rise to the PR crisis a problem of potential dishonesty on the part of the company or of a lack of vigilance? Our recommendation: send out the babyface when the issue is one of dishonesty and the mature face when it is one of lack of vigilance.

\section{APPENDIX STIMULI USED IN EXPERIMENT 4}

\section{YAHOO! NEWS ARTICLE}

\section{First Two Paragraphs}

Hong Kong (Reuters)-Biomedic Ltd, a Hong Kong based pharmaceutical company, has named Frank Leung as its president and CEO replacing the outgoing Henry Yip.

The change in leadership at Biomedic comes after Yip, who led the company for six years, stepped down in July after disappointing second quarter financial results, largely due to the failure of their new cold remedy "Coughless". Soon after its introduction last winter, Coughless was found to have a side effect- $1 \%$ of users developed headaches. The company and CEO Yip were severely criticized for not mentioning possible headaches in the information sheet that comes inside the box of Coughless tablets. A number of consumers filed a lawsuit against the firm for intentional deception.

\section{Third Paragraph for Honesty-in-Doubt Scenario}

According to the lawyer for the victims, "Henry must have known the side effect before he put the Coughless on market. This is one of the clearest cases of intentional deception I have ever seen. Biomedic just wasn't honest with consumers and it should have been. This must not happen again", he emphasized. Whatever the outcome of the lawsuit, the publicity this issue has generated is likely the main reason for the significant reduction in Biomedic's sales and profits this year.

\section{Third Paragraph for Vigilance-in-Doubt Scenario}

According to a company spokesman, "Henry should have acted more responsibly. When our scientists said that the results of their research showed that Coughless had no side effects and was ready to go to market, Henry should have insisted on more research-more tests and more complete ones. They would have revealed the side effect of headaches. Henry was too naïve and took the scientists' words at face value. He did not check the facts thoroughly. This won't happen again", he emphasized. Whatever the outcome of the lawsuit, the publicity this issue has generated is likely the main reason for the significant reduction in Biomedic's sales and profits this year.

\section{REFERENCES}

Ahluwalia, Rohini, Robert E. Burnkrant, and H. R. Unnava (2000), "Consumer Response to Negative Publicity: The Moderating Role of Commitment," Journal of Marketing Research, 37 (2), 203-14.

$\rightarrow$ Berry, Diane S. and Sheila Brownlow (1989), "Were the Physiognomists Right? Personality Correlates of Facial Babyishness," Personality and Social Psychology Bulletin, 15 (2), 266-79.

Berry, Diane S. and Leslie Z. McArthur (1985), "Some Components and Consequences of a Babyface," Journal of Personality and Social Psychology, 48 (2), 312-23.

$\rightarrow$ Brownlow, Sheila (1992), "Seeing Is Believing: Facial Appearance, Credibility, and Attitude Change," Journal of Nonverbal Behavior, 16 (2), 101-15.

Chartrand, Tanya L. and John A. Bargh (1996), "Automatic Activation of Impression Formation and Memorization Goals: Nonconscious Goal Priming Reproduces Effects of Explicit Task Instructions," Journal of Personality and Social Psychology, 71 (3), 464-78.

Frazier, Mya (2006), "Edelman Eats Humble Pie," Advertising Age, http://www.adage.com/, electronically published October 19.

$\rightarrow$ Friedman, Heidi and Leslie A. Zebrowitz (1992), "The Contribution of Typical Sex Differences in Facial Maturity to Sex Role Stereotypes," Personality and Social Psychology Bulletin, 18 (4), 430-38.

Gilbert, Daniel T. (1989), "Thinking Lightly about Others: Automatic Components of the Social Inference Process," in Unintended Thoughts, ed. Jim S. Uleman and John A. Bargh, New York: Guilford, 189-211.

Gilbert, Daniel T. and Douglas S. Krull (1988), "Seeing Less and Knowing More: The Benefits of Perceptual Ignorance," Journal of Personality and Social Psychology, 54 (2), 193-202.

Gladwell, Malcolm (2005), Blink: The Power of Thinking without Thinking, New York: Little, Brown.

$\rightarrow$ Johar, Gita Venkataramani (1996), "Intended and Unintended Effects of Corrective Advertising on Beliefs and Evaluations: An Exploratory Analysis," Journal of Consumer Psychology, 5 (3), 209-30.

$\rightarrow$ Johar, Gita Venkataramani, Jaideep Sengupta, and Jennifer Aaker (2005), "Two Roads to Updating Brand Personality Impressions: Trait versus Evaluative Inferencing," Journal of Marketing Research, November, 458-69.

$\rightarrow$ McArthur, Leslie Z. and Karen Apatow (1983-84), "Impressions of Baby-Faced Adults," Social Cognition, 2 (4), 315-42.

$\rightarrow$ Sengupta, Jaideep, Darren W. Dahl, and Gerald J. Gorn (2002), "Misrepresentation in the Consumer Context," Journal of Consumer Psychology, 12 (2), 69-79.

Zebrowitz, Leslie A. (1997), Reading Faces: Window to the Soul? Boulder, CO: Westview. 
$\rightarrow$ Zebrowitz, Leslie A. and Susan M. McDonald (1991), "The Impact of Litigants' Baby-Facedness and Attractiveness on Adjudications in Small Claims Courts," Law and Human Behavior, 15 (6), 603-23.

$\rightarrow$ Zebrowitz, Leslie A., Daniel R. Tenenbaum, and Lori H. Goldstein (1991), “The Effect of Job Applicants' Facial Maturity, Gen- der, and Academic Achievement on Hiring Recommendations," Journal of Applied Social Psychology, 21 (7), 525-48. $\rightarrow$ Zemborain, Martin R. and Gita V. Johar (2007), "Attitudinal Ambivalence and Openness to Persuasion: A Framework for Interpersonal Influence," Journal of Consumer Research, 33, 506-14. 